\title{
PREVALENCE OF MOLAR INCISOR HYPOMINERLIZATION AMONG A GROUP OF EGYPTIAN CHILDREN: A CROSS-SECTIONAL STUDY
}

\author{
Aya Refaat Abd El Ghaffar*, Sara Ahmed Mahmoud** and Marwa Aly Fouad***
}

\begin{abstract}
Objective: This study aimed to determine the prevalence of molar incisor hypomineralization (MIH) among a group of Egyptian children aged 8-12 years old in Giza Governorate.

Material and methods: This study was conducted in Al-Ayat in Mounira Farghally and Aldenaweya schools in Giza, Egypt. The sample size was 371 students.All the students aged 8-12 years who attended school on the day of examination were examined for the presence or absence of MIH. MIH was recorded when at least one of the first permanent molars shows any of the diagnostic criteria of MIH according to the modified index developed in line with European Academy of Paediatric Dentistry criteria.

Results: The gender distribution among the participants was 191 boys (51.5\%) and 180 girls $(48.5 \%)$. The mean $(\mathrm{SD})$ values for age were $10.1( \pm 1.4)$ years with a minimum of 8 and a maximum of 12 years old. MIH was found in 10 children giving a prevalence of $2.7 \%$ among the examined children. The majority of the children (70\%) diagnosed with MIH presented lesions in both permanent first molars and incisors with different degrees, and 30\% of them presented lesions in permanent first molars only.
\end{abstract}

Conclusions: The prevalence of MIH among the study sample was $2.7 \%$. The most prevalent defect reported in this study was demarcated opacity. The most common degree of severity of MIH in the studied population was the mild degree.

\section{INTRODUCTION}

The term molar incisor hypomineralization (MIH) was first introduced in 2001 by Weerheijm et al. to refer to the clinical appearance of enamel hypomineralization of systemic origin which affect one or more first permanent molars (FPMs) that are commonly associated with affected incisors (Weerheijm et al., 2001 and Allazzam et al., 2014).

\footnotetext{
* MSC Student Masters Degree in Pediatric Dentistry and Dental Public Health Faculty of Dentistry, Cairo University. ** Associate Professor In Pediatric Dentistry and Dental Public Health, Faculty of Dentistry, Cairo University. *** Instructor in Pediatric Dentistry and Dental Public Health, Faculty of Dentistry, Cairo University.
} 
MIH is a developmental, qualitative enamel defect caused by reduced mineralization and inorganic enamel components that ends up in enamel discoloration and fractures of the affected teeth. Initially, the condition was termed as affecting the first permanent molars and incisors but more recently it has been noted that these defects could affect any primary or permanent tooth (Almuallem and Busuttil-Naudi, 2018).

The causative mechanism of MIH remains unclear, but the clinical presentation of localized and asymmetrical lesions suggests a systemic origin with the disturbance during the amelogenesis process most likely occurring within the early maturation stage or even earlier at the late secretory phase (Weerheijm, 2004 and Saber et al., 2018)

MIH increases dental caries risk of affected teeth because teeth not only have soft and porous enamel but are also very sensitive to stimuli making effective oral hygiene difficult.Clinicians face significant challenges with $\mathrm{MIH}$, with the contemporary approaches to its restorative treatment remaining relatively ineffective (Crombie et al., 2009).

The available data regarding $\mathrm{MIH}$ prevalence from studies performed within the Middle East is deficient relative to the data from the studies performed in Western Europe. Therefore, this study aimed to assess the prevalence of MIH among a group of Egyptian children aged from 8 to 12 years in Giza Governorate.

\section{MATERIALS AND METHODS}

\section{Sample Size Calculation}

The sample size was calculated to determine the minimum proper sample size for the prevalence of molar incisor hypomineralization among Egyptian children in Giza governorate. Reviewing the literature revealed that the prevalence in similar situations ranged from $0.48 \%$ to $40.7 \%$ with an average of $20 \%$. Assuming that the true prevalence may change $\pm 5 \%$, it is needed to survey 371 children to be able to achieve $80 \%$ power, setting the alpha error to 0.05 and the margin of error at $5 \%$ the sample became 371. Sample size calculation was done using StatCalc, Epi Info version 7 for MS Windows, Centers for Disease Control and Prevention (CDC), USA . (Al-Hammad t al., 2018).

\section{Ethics approval}

The research protocol was approved by the Research Ethics Committee at the Faculty of Dentistry, Cairo University, on 17/4/2018

\section{Selection of samples}

The study was conducted in two public schools in Al-Ayat. Mounira Farghally and Aldenaweya schools were randomly selected in Giza, Egypt in year 2019. All the students aged 8-12 years who attended school on the day of examination were examined for the presence or absence of molar incisor hypomineralization and its severity. Both genders were examined according to inclusion and exclusion criteria:

\section{Eligibility criteria}

\section{(A) Inclusion criteria:}

1. Children in Giza governorate.

2. Students age from 8-12years.

3. Positive patient acceptance for participation in the study.

4. Patients who are apparently medically free from any systemic disease.

\section{(B) Exclusion criteria:}

1. Students with a history of systemic diseases.

2. Uncooperative children.

3. Children wearing dental appliances.

Before the beginning of the study, the basic education about MIH and its possible differential diag- 
nosis of different enamel defects took place in the form of detailed definitions and diagnostic criteria along with methods to differentiate between them clinically, all were saved in a PowerPoint presentation that was available for the single final evaluator who was Master's Degree student in Pediatric Dentistry and Dental Public Health Department at Faculty of dentistry, Cairo University.

\section{Screening}

A specially designed chart was used to record the presence/absence of molar incisor hypomineralization and its severity based on EAPD criteria 2009 (Sönmez et al., 2013).

\section{Enrolled subjects:}

Students were either free of MIH and got dismissed however contributed in being part of the sample, or diagnosed with MIH when at least one of the first permanent molars shows any of the diagnostic criteria of MIH according to the modified index developed in line with European Academy of Paediatric Dentistry criteria (table 1) (Weerheijm et al., 2003).

TABLE (1): Modified index developed in line with EAPD criteria

\begin{tabular}{cll}
\hline Code & Description & Severity \\
\hline 0 & No defect & \\
\hline 1 & White or creamy demarcated opacities & Mild \\
\hline 2 & Yellow or brown demarcated opacities & Mild \\
\hline $3 \mathrm{a}$ & Enamel loss & Moderate \\
\hline $3 \mathrm{~b}$ & Enamel and dentine loss & Moderate \\
\hline $3 \mathrm{c}$ & $\begin{array}{l}\text { Atypical large cavities extending to pulp } \\
\text { and covering one or more tubercle }\end{array}$ & Severe \\
\hline 4 & Atypical restorations & Severe \\
\hline 5 & Extracted tooth & Severe \\
\hline
\end{tabular}

Clinical examination was made while the child is seated in an ordinary chair in the daylight using disposable diagnostic sets (mirror and probe) according to WHO criteria 2013 (Koruyucu et al., 2018). Teeth were examined in a wet condition according to (Weerheijm et al., 2003) The index teeth including the eight incisors and the four $1 \mathrm{st}$ permanent molars were cleaned using a cotton roll and a probe was used for cleaning the molars' fissures.

\section{Scoring of MIH}

The coronal part of the four first permanent molars and eight permanent incisors were carefully inspected for the presence of demarcated opacities in each child.

At least one affected first permanent molar was required for a diagnosis of molar incisor hypomineralization. In the case of an extracted first permanent molar, it was recorded as affected if another first permanent molar had a defect indicating molar incisor hypomineralization (Sönmez et al., 2013).

\section{Statistical analysis}

Qualitative data were presented as frequencies and percentages. Fisher's Exact Test was used for comparisons concerning qualitative variables. Quantitative data were presented as mean, standard deviation (SD), and 95\% Confidence Interval (95\% CI) for the mean value. Quantitative data were discovered for normality by checking the distribution of data and using tests of normality (Kolmogorov-Smirnov and Shapiro-Wilk tests). The student's t-test was used to compare between patients with and without MIH. The significance level was set at $\mathrm{P} \leq 0.05$. Statistical analysis was performed with IBM SPSS Statistics for Windows, Version 23.0. Armonk, NY: IBM Corp. 


\section{RESULTS}

In the present study, a total of 371 children from the Giza governorate were screened for the presence of MIH and its severity.

$\mathrm{MIH}$ was found in 10 children from the total sample (371), giving a prevalence of $2.7 \%$.

\section{Demographic data:}

The gender distribution among the participants was 191 boys (51.5\%) and 180 girls (48.5\%). The mean $(\mathrm{SD})$ values for age were $10.1( \pm 1.4)$ years with a minimum of 8 and a maximum of 12 years old.

\section{Prevalence (Frequency) of EAPD scores in the incisor teeth}

For the upper incisors; the prevalence of scores 0 and 1 was the same in the left and right sides (40\% and 20\%, respectively). Score 2 showed lower prevalence in the left side compared to the right side (20\% and $30 \%$, respectively), while score $3 \mathrm{a}$ was only found on the left side (20\%). Score $3 b$ was only found in one case (10\%) affecting the upper right incisor.
While for the lower incisors; the prevalence of scores $0,1,2$, and $3 \mathrm{a}$ was the same in the left and right sides $(50 \%, 10 \%, 30 \%$, and $10 \%$, respectively) as shown in table (2)

\section{Prevalence (frequency) of EAPD scores in the molar teeth}

For the upper molars; left molars showed a lower prevalence of Score 0 than right molars $(70 \%$ and $80 \%$, respectively) and a higher prevalence of Score 1 than right molars (20\% and $10 \%$, respectively). Both sides showed the same prevalence of Score 3c $(10 \%)$.

While for the lower molars; the left molars showed a higher prevalence of Score 0 than right molars (10\% and $0 \%$, respectively). Both sides showed the same prevalence of Score $1(10 \%)$. Left molars showed a higher prevalence of Score 2 than right molars (60\% and $30 \%$, respectively). The left molars showed a lower prevalence of Scores $3 \mathrm{~b}$ and $3 \mathrm{c}$ than right molars $(0 \%$ and $30 \%$ for both scores, respectively). The left molars showed a higher prevalence of Score 4 than right molars $(20 \%$ and $0 \%$, respectively) as shown in table (3).

TABLE (2): Frequencies (n) and percentages (\%) for the EAPD scores in incisor teeth of cases with MIH $($ number $(\mathrm{n})=10)$

\begin{tabular}{|c|c|c|c|c|c|c|c|c|}
\hline \multirow[t]{2}{*}{ Scores } & \multicolumn{2}{|c|}{$\begin{array}{c}\text { Upper.left incisors } \\
\text { (ULI) }\end{array}$} & \multicolumn{2}{|c|}{$\begin{array}{l}\text { Upper.right incisors } \\
\text { (URI) }\end{array}$} & \multicolumn{2}{|c|}{$\begin{array}{l}\text { Lower.left incisors } \\
\text { (LLI) }\end{array}$} & \multicolumn{2}{|c|}{$\begin{array}{l}\text { Lower.right incisors } \\
\text { (LRI) }\end{array}$} \\
\hline & $\mathrm{n}$ & $\%$ & $\mathrm{n}$ & $\%$ & $\mathrm{n}$ & $\%$ & $\mathrm{n}$ & $\%$ \\
\hline No defect (Score 0) & 4 & 40 & 4 & 40 & 5 & 50 & 5 & 50 \\
\hline Mild (Score 1) & 2 & 20 & 2 & 20 & 1 & 10 & 1 & 10 \\
\hline Mild (Score 2) & 2 & 20 & 3 & 30 & 3 & 30 & 3 & 30 \\
\hline Moderate (Score 3a) & 2 & 20 & 0 & 0 & 1 & 10 & 1 & 10 \\
\hline Moderate (Score 3b) & 0 & 0 & 1 & 10 & 0 & 0 & 0 & 0 \\
\hline Severe (Score 3c) & 0 & 0 & 0 & 0 & 0 & 0 & 0 & 0 \\
\hline Severe (Score 4) & 0 & 0 & 0 & 0 & 0 & 0 & 0 & 0 \\
\hline Severe (Score 5) & 0 & 0 & 0 & 0 & 0 & 0 & 0 & 0 \\
\hline
\end{tabular}


TABLE (3): Frequencies (n) and percentages (\%) for the EAPD scores in molar teeth of cases with MIH $(\mathrm{n}=10)$

\begin{tabular}{|c|c|c|c|c|c|c|c|c|}
\hline \multirow[t]{2}{*}{ Severity } & \multicolumn{2}{|c|}{$\begin{array}{l}\text { Upper left molar } \\
\text { (ULM) }\end{array}$} & \multicolumn{2}{|c|}{$\begin{array}{l}\text { Upper right molar } \\
\text { (URM) }\end{array}$} & \multicolumn{2}{|c|}{$\begin{array}{l}\text { Lower left molar } \\
\text { (LLM) }\end{array}$} & \multicolumn{2}{|c|}{$\begin{array}{c}\text { Lower right molar } \\
\text { (LRM) }\end{array}$} \\
\hline & $\mathrm{n}$ & $\%$ & $\mathrm{~N}$ & $\%$ & $\mathrm{n}$ & $\%$ & $\mathrm{n}$ & $\%$ \\
\hline No defect (Score 0) & 7 & 70 & 8 & 80 & 1 & 10 & 0 & 0 \\
\hline Mild (Score 1) & 2 & 20 & 1 & 10 & 1 & 10 & 1 & 10 \\
\hline Mild (Score 2) & 0 & 0 & 0 & 0 & 6 & 60 & 3 & 30 \\
\hline Moderate (Score 3a) & 0 & 0 & 0 & 0 & 0 & 0 & 0 & 0 \\
\hline Moderate (Score 3b) & 0 & 0 & 0 & 0 & 0 & 0 & 3 & 30 \\
\hline Severe (Score 3c) & 1 & 10 & 1 & 10 & 0 & 0 & 3 & 30 \\
\hline Severe (Score 4) & 0 & 0 & 0 & 0 & 2 & 20 & 0 & 0 \\
\hline Severe (Score 5) & 0 & 0 & 0 & 0 & 0 & 0 & 0 & 0 \\
\hline
\end{tabular}

\section{MIH Severity according to EAPD in the incisor} teeth

For the upper incisors; the prevalence of no defect was the same in the left and right sides (40\% and $40 \%$, respectively). The Left side showed a lower prevalence of mild defect than the right side (40\% and 50\%, respectively). The Left side showed a higher prevalence of moderate defect than the right side (20\% and $10 \%$, respectively).

While for the lower incisors; the prevalence of no defect, mild and moderate defects was the same in the left and right sides (50\%, 40\%, and 10\%, respectively) as shown in table (4).

TABLE (4): Frequencies (n) and percentages (\%) for the severity according to EAPD in incisor teeth of cases with MIH $(\mathrm{n}=10)$

\begin{tabular}{|c|c|c|c|c|c|c|c|c|}
\hline \multirow{2}{*}{ Severity } & \multicolumn{2}{|c|}{$\begin{array}{l}\text { Upper left incisors } \\
\text { (ULI) }\end{array}$} & \multicolumn{2}{|c|}{$\begin{array}{l}\text { Upper right incisors } \\
\text { (URI) }\end{array}$} & \multicolumn{2}{|c|}{$\begin{array}{l}\text { Lower left incisors } \\
\text { (LLI) }\end{array}$} & \multicolumn{2}{|c|}{$\begin{array}{l}\text { Lower right incisors } \\
\text { (LRI) }\end{array}$} \\
\hline & $\mathrm{n}$ & $\%$ & $\mathrm{n}$ & $\%$ & $\mathrm{n}$ & $\%$ & $\mathrm{n}$ & $\%$ \\
\hline No defect & 4 & 40 & 4 & 40 & 5 & 50 & 5 & 50 \\
\hline Mild defect & 4 & 40 & 5 & 50 & 4 & 40 & 4 & 40 \\
\hline Moderate defect & 2 & 20 & 1 & 10 & 1 & 10 & 1 & 10 \\
\hline
\end{tabular}




\section{MIH Severity according to EAPD in the molar teeth}

For the upper molars; the left molars showed a lower prevalence of no defects than right molars (70\% and $80 \%$, respectively) and a higher prevalence of mild defects than right molars $(20 \%$ and $10 \%$, respectively). Both sides showed the same prevalence of severe defects $(10 \%)$.

While for the lower molars; the left molars showed a higher prevalence of no defects than right molars (10\% and $0 \%$, respectively). The left molars also showed a higher prevalence of mild defects than right molars (70\% and $40 \%$, respectively). The left molars showed a lower prevalence of moderate defects than the right molars $(0 \%$ and $30 \%$, respectively). The left molars also showed a lower prevalence of severe defects than right molars (20\% and 30\%, respectively) as shown in (table 5).

TABLE (5): Frequencies (n) and percentages (\%) for the severity according to EAPD in molar teeth of cases with MIH ( $=10)$

\begin{tabular}{lcccccccc}
\hline \multirow{2}{*}{ Severity } & $\begin{array}{c}\text { Upper left molar } \\
\text { (ULM) }\end{array}$ & $\begin{array}{c}\text { Upper right molar } \\
\text { (URM) }\end{array}$ & $\begin{array}{c}\text { Lower left molar } \\
\text { (LLM) }\end{array}$ & $\begin{array}{c}\text { Lower right molar } \\
\text { (LRM) }\end{array}$ \\
\cline { 2 - 9 } & $\mathrm{n}$ & $\%$ & $\mathrm{n}$ & $\%$ & $\mathrm{~N}$ & $\%$ & $\mathrm{n}$ & $\%$ \\
\hline No defect & 7 & 70 & 8 & 80 & 1 & 10 & 0 & 0 \\
Mild defect & 2 & 20 & 1 & 10 & 7 & 70 & 4 & 40 \\
Moderate defect & 0 & 0 & 0 & 0 & 0 & 0 & 3 & 30 \\
Severe defect & 1 & 10 & 1 & 10 & 2 & 20 & 3 & 30 \\
\hline
\end{tabular}

\section{DISCUSSION}

Prevalence studies are important for both patients and dental practitioners to apply appropriate measures to limit the effect of MIH. As the data on the prevalence of MIH in Middle East countries is deficient, this study aimed to evaluate the prevalence of MIH in a group of Egyptian children aged 8-12 years old in Giza Governorate (Osman et al., 2020).

This observational (cross-sectional) study included 371 students that were examined for the presence or absence and severity of molar incisor hypomineralization in Giza governorate. From Mounira Farghally school 221 students were examined and 150 students were examined from Aldenaweya school.Only Egyptian children from Giza governorate were included in this study to minimize variables that could affect the results. Large-scale studies in child populations are difficult to perform, particularly when a specific problem is to be determined. Precise calibration of the examiners is needed, therefore in many previous studies, only part of a particular child population was examined for the presence and prevalence of MIH ( Jälevik et al., 2001 and $\mathrm{Ng}$ et al., 2015 ).

MIH was found in ten children giving a prevalence of $2.7 \%$ among the examined children in Giza governorate which is in the limit with the global prevalence of MIH that has been estimated to range from 2.4 to $40.2 \%$ with an estimated mean of 13.1 to $14.2 \%$ (Abdalla et al., 2020), and the Egyptian prevalence which was $2.3 \%$ to $14.2 \%$ according to the studies of Saber et al., 2018 and Osman et al., 2020. 
However, this prevalence was lower than the estimated prevalence in middle and southeast Asian countries that ranges from $9.25 \%$ to $20.2 \%$ (Rai et al., 2019 and Davenport et al., 2019). Other studies showed various prevalence rates as India (0.48\%), Hong Kong (2.8\%), Brazil (40.2\%) ,Lebanon(26.7\%) Dubai (27.2\%), Nigeria (17.7\%) ,Kenya (13.7\%) and Libya (2.9\%) (Fteita et al., 2006 ; Kemoli, 2008 ; Soviero et al., 2009 ; Oyedele et al., 2015 and Abdalla et al., 2020).

The present study showed that MIH occurs more in the mandible than in the maxilla which is in agreement with Jälevik et al., 2001 and Yannam et al., 2016, and in contrast to the results of AlHammad et al., 2018 and Hamdan et al., 2020. Several factors can explain the arch difference of $\mathrm{MIH}$ prevalence as maxillary and mandibular molars may be examined under differing conditions. The sitting position of children during the examination, the lighting source can obscure the lesions of MIH in maxillary molars, and whether teeth were examined wet or dry. The higher prevalence of MIH in the mandible could also be due to earlier eruption than maxillary molars (Zawaideh et al., 2011 and Thakur et al., 2020)

The present study found that $70 \%$ of the children diagnosed with MIH presented lesions in both permanent first molars and incisors with different degrees, and $30 \%$ of them presented lesions in first permanent molars only. Severely affected first permanent molars in this study were; in the upper molars, both sides showed the same prevalence of severe defects. In the lower molars, the left molars also showed a lower prevalence of severe defects than the right molars. This may be explained by the fact that enamel loss due to occlusal load may lead to a rapid progression of caries, and because of the sensitivity associated with MIH, children avoid brushing, destroying the affected teeth.

The affected incisors revealed mild and moderate severity of MIH with a higher rate of opacities. This finding tended to be in line with most other studies in which affected incisors have rarely exhibited posteruptive breakdown because of the absence of masticatory forces upon these surfaces (Preusser et al., 2007 and Kirthiga et al., 2015)

Finally, MIH defects can influence the general health and quality of life of an affected child, and its treatment is often challenging to both the patient and clinician. For patients and dentists to apply appropriate measures to limit the effect of $\mathrm{MIH}$ and for policymakers to have a reliable picture of the defect characteristics in a specific population, the different parameters of MIH should be assessed (Ghanim et al., 2015 and Rodd et al., 2021).

\section{CONCLUSIONS}

From the results of this study, the following can be concluded:

1. The prevalence of $\mathrm{MIH}$ among a group of Egyptian children aged 8-12 years in Giza Governorate was $2.7 \%$.

2. There is no statistically significant difference between gender and the prevalence of MIH.

3. MIH occurs more in the mandible than in the maxilla and occurs in molars teeth more than incisors teeth.

4. The most prevalent defect reported in this study was demarcated opacity.

5. The most common degree of severity of MIH in this studied population was the mild degree.

\section{Study limitations:}

- Diagnosis of MIH was made by inspection under the daylight. This may have resulted in the examiner missing some cases of $\mathrm{MIH}$ and possible confusion with other enamel defects.

- Another possible limitation for this study may be the association of MIH with a past medical history which was not possible to record due to the absence of the child's medical records in the schools and the non-availability of the parents. 
- The difficulty of needed legal approvals.

- The study was done during the school day so the teachers were in a hurry so that the lessons would not be disrupted.

- Taking pictures for the cases was not so easy because of the large number of participants related to the time of school day.

\section{RECOMMENDATIONS}

1. Further studies with a larger sample are needed to study the prevalence and severity of MIH in different governorates in Egypt.

2. Further studies should be performed to determine the possible etiology and risk factors for MIH.

3. Regular follow-up and recall program for children affected with MIH for the application of the appropriate preventive and therapeutic measures.

4. There is also a need for formulating public awareness and preventive programs for MIH.

5. Special attention should be given to determine if particular health conditions affect the prevalence of MIH.

\section{REFERENCES}

1. Abdalla, H. E., Abuaffan, A. H., \& Kemoli, A. M. (2020). Molar Incisor Hypomineralization, prevalence, pattern and distribution in Sudanese children. https://doi.org/10.21203/ rs.3.rs $43683 / \mathrm{v} 2$

2. Al-Hammad, N. S., Al-Dhubaiban, M., Alhowaish, L., \& Bello, L. L. (2018). Prevalence and Clinical Characteristics of Molar-Incisor-Hypomineralization in School Children in Riyadh, Saudi Arabia. Int. J. Med. Sci. Clin. Invent., 5(3), 3570-3576. https://doi.org/10.18535/ijmsci/v5i3.01

3. Allazzam, S. M.,Alaki, S. M., \& El Meligy, O.A. S. (2014). Molarincisor hypomineralization, prevalence, and etiology. Int. J. Dent., 2014. https://doi.org/10.1155/2014/234508

4. Almuallem, Z., \& Busuttil-Naudi, A. (2018). Molar incisor hypomineralisation (Mih) - an overview. Br. Dent. J., 225(7), 601-609. https://doi.org/10.1038/sj.bdj.2018.814

5. Crombie, F., Manton, D., \& Kilpatrick, N. (2009). Aetiology of molar-incisor hypomineralization: A critical review. In International Journal of Paediatric Dentistry
(Vol. 19, Issue 2, pp. 73-83). John Wiley \& Sons, Ltd. https://doi.org/10.1111/j.1365-263X.2008.00966.x

6. Davenport, M., Welles, A. D., Angelopoulou, M. V., Gonzalez, C., Okunseri, C., Barbeau, L., Bansal, N. K., Vergotine, R. J., \& Hodgson, B. D. (2019). Prevalence of molar-incisor hypomineralization in milwaukee, wisconsin, USA: A pilot study. Clin. Cosmet. Investig. Dent., 11, 109-117. https://doi.org/10.2147/CCIDE. S172736

7. Fteita, D., Ali, A., \& Alaluusua, S. (2006). Molar-incisor hypomineralization (MIH) in a group of school-aged children in Benghazi, Libya. Eur. Arch. Paediatr. Dent., 1(2), 92-95. https://doi.org/10.1007/bf03320821

8. Ghanim, A., Elfrink, M., Weerheijm, K., Mariño, R., \& Manton, D. (2015). A practical method for use in epidemiological studies on enamel hypomineralisation. Eur. Arch. Paediatr. Dent., 16(3), 235-246. https://doi. org/10.1007/s40368-015-0178-8

9. Hamdan, M., Abu-Ghefreh, E., Al-Abdallah, M., \& Rajab, L. (2020). The prevalence and severity of molar incisor hypomineralization (MIH) among 8 year-old children in Amman, Jordan. Egypt. Dent. J., 66(4), 1989-1997. https://doi.org/10.21608/edj.2020.35468.1182

10. Jälevik, Birgitta, Klingberg, G., Barregård, L., \& Norén, J. G. (2001). The prevalence of demarcated opacities in permanent first molars in a group of Swedish children. Acta Odontol. Scand., 59(5), 255-260. https://doi. org/10.1080/000163501750541093

11. Kemoli, A. M. (2008). Prevalence of molar incisor hypomineralisation in six to eight year-olds in two rural divisions in Kenya. East Afr. Med. J., 85(10), 514-519. https://doi.org/10.4314/eamj.v85i10.9668

12. Kirthiga, M., Poornima, P., Praveen, R., Gayathri, P., Manju, M., \& Priya, M. (2015). Prevalence and severity of molar incisor hypomineralization in children aged 11-16 years of a city in Karnataka, Davangere. J. Indian Soc. Pedod. Prev. Dent., 33(3), 213-217. https://doi. org/10.4103/0970-4388.160366

13. Koruyucu, M., Özel, S., \& Tuna, E. B. (2018). Prevalence and etiology of molar-incisor hypomineralization (MIH) in the city of Istanbul. J. Dent. Sci., 13(4), 318-328. https:// doi.org/10.1016/j.jds.2018.05.002

14. Ng, J. J., Eu, O. Y. C. H. U., Nair, R., Hsu, C., \& Hong, L. (2015). Prevalence of molar incisor hypomineralization 
(MIH) in Singaporean children. 73-78. https://doi. org/10.1111/ipd.12100

15. Osman, S., Elmasry, E., \& Abd Al Gawad, R. (2020). Prevalence of Molar Incisor Hypominerlization among a Group of Egyptian Children: A Cross Sectional study. Egypt. Dent. J., 66(4), 2021-2028. https://doi. org/10.21608/edj.2020.40437.1222

16. Oyedele, T. A., Folayan, M. O.,Adekoya-Sofowora, C. A., Oziegbe, E. O., \& Esan, T. A. (2015). Prevalence, pattern and severity of molar incisor hypomineralisation in 8- to 10-year-old school children in Ile-Ife, Nigeria. Eur. Arch. Paediatr. Dent., 16(3), 277-282. https://doi.org/10.1007/ s40368-015-0175-y

17. Preusser, S. E., Ferring, V., Wleklinski, C., \& Wetzel, W. E. (2007). Prevalence and severity of molar incisor hypomineralization in a region of Germany - A brief communication. J. Public Health Dent., 67(3), 148-150. https://doi.org/10.1111/j.1752-7325.2007.00040.x

18. Rai, P. M., Jain, J., Raju, A. S., Nair, R. A., Shashidhar, K., \& Dsouza, S. (2019). Prevalence of molar incisor hypomineralization among school children aged 9 to 12 years in Virajpet, Karnataka, India. Open Access Maced. J. Med. Sci., 7(6), 1042-1046. https://doi.org/10.3889/ oamjms.2019.224

19. Rodd, H. D., Graham, A., Tajmehr, N., Timms, L., \& Hasmun, N. (2021). Molar Incisor Hypomineralisation: Current Knowledge and Practice. Int. Dent. J. https://doi. org/10.1111/idj.12624

20. Saber, Waly, N., \& Moheb, D. (2018). Prevalence of molar incisor hypomineralisation in a group of Egyptian children using the short form: a cross-sectional study. Eur. Arch. Paediatr. Dent., 19(5), 337-345. https://doi.org/10.1007/ s40368-018-0364-6

21. Sönmez, Yildirim, G., \& Bezgin, T. (2013). Putative factors associated with molar incisor hypomineralisation: An epidemiological study. Eur. Arch. Paediatr. Dent., 14(6), 375-380. https://doi.org/10.1007/s40368-013-0012-0
22. Soviero, V., Haubek, D., Trindade, C., Da Matta, T., \& Poulsen, S. (2009). Prevalence and distribution of demarcated opacities and their sequelae in permanent 1 st molars and incisors in 7 to 13-year-old Brazilian children. Acta Odontol. Scand., 67(3), 170-175. https://doi. org/10.1080/00016350902758607

23. Thakur, H., Kumar, S., Kaur, A., Singh, N., \& Singh, R. (2020). Prevalence and Clinical Characteristics of MolarIncisor Hypomineralization in 8-16-year-old Children in Industrial Town of Solan District of Himachal Pradesh. Int. J. Clin. Pediatr. Dent., 13(3), 230-234. https://doi. org/10.5005/jp-journals-10005-1767

24. Weerheijm, K. L., Jälevik, B., \& Alaluusua, S. (2001). Molar-Incisor Hypomineralisation. Caries Res., 35(5), 390-391. https://doi.org/10.1159/000047479

25. Weerheijm, K. L., Duggal, M., Mejàre, I., Papagiannoulis, L., Koch, G., Martens, L. C., \& Hallonsten, A. L. (2003). Judgement criteria for Molar Incisor Hypomineralisation $(\mathrm{MIH})$ in epidemiologic studies: A summary of the European meeting on MIH held in Athens, 2003. Eur. J. Paediatr. Dent., 4(3), 110-113.

26. Weerheijm,K.L.(2003).Molarincisorhypomineralization : a questionnaire inventory of its occurrence in member countries of the European Academy of Paediatric Dentistry ( EAPD ). 411- 416.

27. Weerheijm,K.L. (2004). Molar incisor hypomineralization (MIH): clinical presentation, aetiology and management. Dent. Update, 31(1), 9-12. https://doi.org/10.12968/ denu.2004.31.1.9

28. Yannam, S. D., Amarlal, D., \& Rekha, C. V. (2016). Prevalence of molar incisor hypomineralization in school children aged 8-12 years in Chennai. J. Indian Soc. Pedod. Prev. Dent., 34(2), 134- 138. https://doi.org/10.4103/09704388.180438

29. Zawaideh, F. I., Al-Jundi, S. H., \& Al-Jaljoli, M. H. (2011). Molar incisor hypomineralisation: Prevalence in Jordanian children and clinical characteristics. Eur. Arch. Paediatr. Dent., 12(1), 31-36. https://doi.org/10.1007/BF03262776 